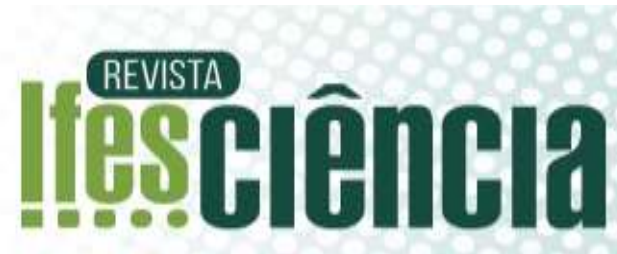

\section{A BIBLIOTECA COMO ESPAÇO DE TRANSFORMAÇÃO SOCIAL E ESTIMULADOR DE LEITURA}

\section{THE LIBRARY AS A SOCIAL TRANSFORMATION SPACE AND READING STIMULATOR}

\author{
Rian Lucas da Silva \\ ${ }^{1}$ Instituto Federal de Educação, Ciência e Tecnologia da Paraíba. E-mail: rian.pd2013@gmail.com
}

Artigo submetido em 13/09/2019, aceito em 04/10/2019 e publicado em 20/12/2019

\begin{abstract}
Resumo: O presente trabalho busca promover um debate sobre as questões que norteiam a prática leitora no contexto sócio escolar, apresentando metodologias que podem ser aplicadas e também remodeladas pelos agentes literários a fim de se obter resultados positivos no que tange à leitura dos textos literários. Este trabalho dá ênfase à biblioteca enquanto espaço em que os discentes podem manter o primeiro contato com as obras literárias, bem como conhecer a importância delas como patrimônio histórico nacional, além de apresentar a leitura como o principal agente de transformação do indivíduo em sociedade. Desse modo, o artigo foi fundamentado por meio de grandes autores, entre os quais se destacam: Candido (1995), Cagliari (1995), Cosson (2007), Rangel (2009) e Bajour (2012) que colaboram ao ofertarem visões que remetem à prática leitora enquanto fator primordial na vida de um sujeito ativo em sociedade. Outrossim, destaca-se o método recepcional das autoras Maria da Glória Bordini e Vera Teixeira Aguiar (1993), sendo representado neste trabalho mediante um modelo de sequência didática que pode ser incorporado pelos agentes literários durante uma aula de Literatura e/ou encontro que se destine à leitura de textos literários e não literários.
\end{abstract}

Palavras-chave: Biblioteca; Leitura literária; Mediador de leitura; Sequência didática.

Abstract: The present work seeks to promote a debate on the issues that guide the reading practice in the socio-school context, presenting methodologies that can be applied and also remodeled by literary agents in order to obtain positive results regarding the reading of literary texts. This work emphasizes the library as a space where students can maintain their first contact with literary works, as well as know their importance as national historical heritage and presents reading as the main agent of transformation of the individual into society. Thus, the article was based on great authors, among which stand out: Candido (1995), Cagliari (1995), Cosson (2007), Rangel (2009) and Bajour (2012) who collaborate in offering views that refer to the reading practice as a primordial factor in the life of an active subject in society. Moreover, the receptive method of the authors Maria da Glória Bordini and Vera Teixeira Aguiar stands out, being represented in this work through a didactic sequence model that can be incorporated by literary agents during a Literature class or meeting intended for reading of literary and non-literary texts.

Keywords: Library; Literary Reading; Reading mediator; Teaching Sequence. 


\section{INTRODUÇÃO}

É indiscutível que a leitura encontrase presente em nossas vidas desde as situações mais habituais, como ler uma bula de medicamento, uma receita de bolo, até às mais complexas, como a leitura de artigos científicos, filosóficos e tantas outras. Desse modo, averigua-se se que a todo momento estamos cercados por palavras, com as quais concordamos, discordamos, interrogamos e/ou interagimos com aquilo que nos cerca. Assim sendo, são infinitas as possibilidades de leitura com as quais podemos nos deparar, ainda mais quando se considera o meio tecnológico no qual estamos inseridos.

Diante disso, um dos problemas apontados ao longo deste trabalho, diz respeito ao desânimo em ler uma determinada obra literária, desânimo esse que, talvez, seja ocasionado pela falta de preparação por parte dos professores quando à abordagem literária abordada durante o percurso de leitura, bem como por não estarem inserindo em suas metodologias, motivações suficientes capazes de ir ao encontro dos objetivos propostos para os discentes.

É justamente nesse panorama que surge o professor como um meio e, sobretudo, como um mediador de leitura, precisando atuar com habilidade de modo que venha desmistificar a leitura literária como desprovida de sentidos e interpretações para os jovens que vivem sob a era da informática.

O Brasil é um país em que a prática leitora é muito menor quando comparado a países mais desenvolvidos, pois de acordo com uma pesquisa da Federação do Comércio do Rio de Janeiro (FecomércioRJ), no ano de 2014, 70\% dos brasileiros não leram um livro sequer e, para piorar, o país dispõe de poucas bibliotecas públicas e quando dispõe são em áreas mais desenvolvidas, deixando a enorme parcela rural longe do universo literário. Ademais, destaca-se o elevado preço dos livros nas lojas físicas e/ou virtuais como outro problema que deve ser debatido e questionado.
Este artigo, portanto, surge da necessidade de questionar o papel da biblioteca em uma sociedade ainda ausente no quesito leitura e, sobretudo, destacar o papel dos agentes literários como fonte principal de disseminação de conhecimento e cultura, levando os alunos a refletirem sobre o mundo e sobre si mesmo por meio das amplas obras literárias disponíveis na escola.

Assim, é primordial conhecer a importância de os agentes literários adotarem novas metodologias que busquem cada vez mais atrair a atenção do leitor para o universo literário. Logo, pensando nessas abordagens e metodologias eficazes, o autor criou um modelo de sequência didática para se trabalhar de forma eficaz textos literários, como o poema, por exemplo, desconsiderando leituras fragmentadas e dando atenção especial às leituras integrais que visem ao real entendimento do texto.

\section{A LEITURA ENQUANTO AGENTE DE MUDANÇA SOCIAL}

Primordialmente, Silva (1991) deixa claro que a leitura desempenha aspectos essenciais na vida de um indivíduo, uma vez que faz com que o leitor descubra sobre o mundo que vive e, sobretudo, sobre si mesmo.

Ainda na visão de Silva (1991), ele mostra que a leitura representa um ato do conhecimento em que tal ato permite a percepção e o entendimento sobre as relações existentes na sociedade.

Desse modo, nota-se a leitura como um processo de produção de sentidos, visando possibilitar cada vez mais o aprendizado, constituindo-se não apenas como uma prática individual, mas também como uma prática social. Sobre isso, Indursky e Zinn (1985, p.56) por meio de seus estudos, comentam:

Assim a produção de leitura consiste no processo de interpretação desenvolvido por um sujeito-leitor que, defrontando-se com um texto, analisa, questiona com o objetivo de processar 
seu significado projetando sobre ele sua visão de mundo para estabelecer uma interação crítica com o texto.

Os autores acreditam que a leitura se desenvolve em meio à relação estabelecida entre leitor-fonte, tendo em vista que o resultado dessa interação provoca a transmissão de informações, concretizando assim, um processo integrado e ininterrupto.

Além desse fator contínuo, a leitura ainda se mostra como uma prática interativa, sendo pontuada como uma das estratégias essenciais no que se refere ao desenvolvimento individual. Sendo assim, durante $o$ percurso de leitura são estabelecidas diversas formas de diálogo entre o leitor e o texto, posto que a interatividade entre ambos se desenvolve de forma natural conforme o leitor processa as informações que foram e serão recebidas.

Contudo, de nada adianta a leitura possuir tantos aspectos positivos no desenvolvimento crítico e autônomo do futuro leitor, se não houver pessoas preparadas o suficiente para propagar esse amor pela leitura. Em outras palavras, faz-se necessário que os docentes desenvolvam o hábito de leitura a fim de se tornarem aptos para exercerem seu papel de mediador, pois é somente por meio da prática leitora de cada um, que será possível transpassar aos alunos o desejo de ler cada vez mais obras literárias.

\section{OS PÁPEIS DOS AGENTES LITERÁRIOS ENQUANTO MEDIADORES DE LEITURA}

A escola permanece sendo o principal lugar de disseminação de leitura, porém, muitas escolas públicas ainda não apresentam boas bibliotecas, muito menos agentes literários que sejam eficientes nessa propagação.

Apesar de ninguém nascer leitor, pois esse processo se constrói ao longo do tempo e precisa ocorrer de modo eficaz, é preciso que se desenvolvam práticas leitoras e, sobretudo, a presença de um mediador, uma vez que de nada adianta ter um bom acervo de livros na escola se não houver alguém que faça esse convite à leitura. Sendo assim, que mediador é esse?

Um fator que não pode ficar de fora quando se fala em mediação, é o conceito de diálogo/dialogicidade, tendo em vista que

\section{"o diálogo é uma exigência existencial. $E$, se ele é o encontro em que se solidarizam o refletir e o agir de seus sujeitos endereçados ao mundo a ser transformado e humanizado, não pode reduzir-se a um ato de depositar ideias de um sujeito no outro, nem tampouco tornar-se simples troca de ideias a serem consumidas pelos permutantes. (...) É um ato de criação. Daí que não possa ser manhoso instrumento de que lance mão um sujeito para a conquista do outro. A conquista implícita no diálogo é a do mundo pelos sujeitos dialógicos, não a de um pelo outro" (Freire, 2010, p. 91).}

$\mathrm{Na}$ afirmação de Paulo Freire (2010), percebe-se que a prática da mediação de leitura se dá pelo diálogo entre os sujeitos, em que esse diálogo é constituído de múltiplas vozes e narrativas.

A partir do diálogo é que a mediação ocorre, sendo manifestada em amplos e diversos lugares, como em centros culturais, ginásios, bibliotecas e muitos outros. Sobre a mediação, Bajour (2012, p. 13) referenda:

Para aqueles que são mediadores entre os leitores e os textos, é enriquecedor pensar como leitura esse momento do bate-papo sobre o lido, o intercâmbio acerca dos sentidos que um texto desencadeia em nós.

Portanto, respondendo ao questionamento apresentado no início, um mediador de leitura é aquele que, primordialmente, gosta de ler, até porque não há como ser um mediador quando não se sente prazer por aquilo que medeia; precisa ser alguém que goste de se comunicar, de falar daquilo que lê e de compartilhar os próprios repertórios de leitura.

Vale ressaltar que, para que a mediação dê frutos e provoque no outro o 
prazer pela leitura, torna-se indispensável que o mediador planeje a leitura com antecedência, além de saber escolher textos que condizem com a situação e nível de entendimentos dos leitores. Segundo Cagliari (1995, p.149):

Ler é um processo de descoberta, como a busca do saber cientifico. Outras vezes requer um trabalho paciente, perseverante, desafiador, semelhante a pesquisa laboratorial. A leitura pode ser também superficial, sem grandes pretensões, uma atividade lúdica, como um jogo de bola em que os participantes jamais se preocupam com a lei da gravidade, a cinética e a balística, mas nem por isso deixam de jogar bola com gosto e perfeição.

Nesse viés, percebe-se que o processo de leitura é muito mais amplo do que aparenta, posto que requer escolha dos textos mais adequados à realidade dos futuros leitores e dos objetivos aos quais se pretendem atingir.

Por isso, o fracasso do leitor pode ser atribuído à ineficácia deste mediador, pois erra quando medeia um processo sem apresentar metodologias condizentes com a realidade escolar, e erra quando não possui um repertório de leitor, pois como um livro pode ser apresentado aos leitores se nem mesmo foi lido pelo mediador? Questionamento como esse precisa ser feito antes mesmo de se iniciar um projeto de leitura em uma escola ou em qualquer outro lugar escolhido.

Logo, não basta somente que o mediador apresente os livros e deixe um longo processo para o leitor. É preciso que o mediador esteja presente em todo o percurso de leitura, sendo um mestre, um ser que guia rumo à descoberta do prazer literário, pois quando o mediador passa a ser esse membro ativo no percurso de leitura, é que a finalidade da literatura se cumpre: promover no indivíduo o desenvolvimento de sua intelectualidade. Nesse sentido, Antonio Candido (1995), explica que a literatura é direito de todo homem, sendo ela um dos motivos principais por consolidar $\mathrm{o}$ universo de conhecimento, assim como os demais direitos básicos do ser humano, indiferentemente de classe social.

\section{A BIBLIOTECA COMO ESPAÇO PROPÍCIO DE DESENVOLVIMENTO DA PRÁTICA LEITORA}

A escola, atualmente, é a responsável por induzir nos alunos o desejo e o prazer pela leitura. Entretanto, são grandes as dificuldades encontradas no que se refere à prática leitora, seja pelo despreparo do mediador de leitura que não aplica metodologias que chamem a atenção do leitor, seja pela constante desmotivação que a maioria dos discentes declaram ter.

Mediante aos diversos problemas relacionados à ausência de leitura, faz-se necessário, portanto, que novas medidas sejam adotadas não só pelos professores, mas também por todos aqueles que sentem o desejo de propagar esse amor pela leitura, isto é, pelos agentes literários, independente de formação acadêmica, tendo em vista que qualquer pessoa pode ser um mediador de leitura na vida de alguém, desde que tenha esse desejo.

Por conseguinte, a biblioteca surge como um ambiente propício de disseminação de conhecimento e amor à leitura, uma vez que apresenta infinitas obras literárias que podem ser vistoriadas e escolhidas pelos alunos, desde que os agentes literários insiram práticas que consigam prender a atenção do educando.

Contudo, não basta apenas existir uma biblioteca, é necessário, primeiramente, que nesse ambiente os leitores se sintam confortáveis. É preciso preparar o local para que os educandos se sintam familiarizados para que, somente depois, dê início às leituras.

No que tange às metodologias que podem ser usadas no ambiente da biblioteca, merecem destaque: o jogo das trocas de palavras, a contação de histórias, o círculo de leitura reflexivo e os quadros comparatórios. 
Sob a ótica do jogo de palavras, é imprescindível a presença de mestre que guie o jogo até o final. Nesse jogo, o educador deve promover a troca de papéis dos personagens entre os leitores, levandoos a interagirem melhor com a obra, colaborando no processo de ensinoaprendizagem e estimulando a criatividade dos alunos mediante as instruções do professor.

A contação de histórias ocorre quando os alunos leem o mesmo livro e se juntam para realizar um debate coletivo. Em tal metodologia os leitores se reúnem na biblioteca em círculo e cada um por vez compartilha sobre seu processo de leitura, contando a história por seu próprio entendimento. Essa prática é importante porque desenvolve a autonomia juntamente com a criatividade dos alunos ao promover uma maior reflexão de como as coisas se desenrolam na mente de cada um.

Os círculos de leitura reflexivos, embora bastante parecidos com a contação de história, dizem respeito a um debate coletivo sobre determinada obra literária ou não. Ou seja, os alunos registram suas primeiras impressões antes de ler determinado livro e quando o finalizam, reúnem-se novamente e comentam sobre suas primeiras impressões, abrindo espaço para refletirem sobre as novas críticas adotadas após ter lido a obra.

Por fim, tem-se a metodologia dos quadros comparativos/comparatórios que se referem a tabelas explicativas e históricas que induzem o consciente do aluno a perceber de que modo tais obras se correlacionam. Isto é, são apresentadas diversas obras e logo após um quadro que exemplifica as ligações presentes entre os textos literários, avaliando as semelhanças e divergências entre ambos.

Logo, trabalhando as metodologias supracitadas o mediador faz com que os alunos concebam o letramento literário como fonte e principal função da literatura escolarizada. Cosson (2007, p. 17) argumenta que a experiência literária não apenas nos permite saber da vida pela experiência do outro, como também vivenciar essa experiência.

Conforme o autor, por possuir essa função de tornar o mundo compreensível transformando sua materialidade em palavras e formas intensamente humanas, é que a literatura tem e precisa manter seu lugar nas escolas. Para que a literatura cumpra esse papel, faz-se necessário mudar os rumos de sua escolarização de maneira a promover o letramento literário.

Por conseguinte, a leitura literária provoca e ao mesmo tempo exige diversos mecanismos de compreensão, ou seja, o texto literário pode dar vazão às mais variadas leituras, a saber, das potencialidades, características e gostos de cada indivíduo que lê.

Ademais, a linguagem literária destaca-se por ser multissignificativa, dialógica, como um meio capaz de provocar emoções distintas em um mesmo leitor. Para Rangel (2009) quanto mais produtivo for o diálogo provocado pelo texto no leitor, mais eficiente será a leitura. Essa característica, aplica-se à leitura literária porque segundo Rangel (2009, p. 27):

o texto comporta uma concepção que não se esgota nele mesmo, mas no diálogo que provoca com o leitor. $\mathrm{O}$ diálogo será tanto mais produtivo quanto mais o texto puder possibilitar condições de identificação do leitor com ele, considerando que o autor, ao criar o texto, não tem objetivo de conformar o leitor, mas de tê-lo como coprodutor, parceiro, dando-lhe também possibilidades de criar outros textos. A obra, então, não é apenas um objeto que apresenta uma visão de mundo acabado, mas um espaço que pode contribuir na formação do leitor reflexivo.

Portanto, a leitura literária se destaca como fator primordial na formação de um indivíduo autônomo e crítico-reflexivo, uma vez que o possibilita a pensar a respeito de sua vida, da sua sociedade e, principalmente, sobre si mesmo.

Pensando nisso, quando se lê um texto de caráter literário são estabelecidas manifestações socioculturais, em que se 
ampliam o conhecimento de mundo do indivíduo enquanto sujeito histórico.

\section{MODELO DE SEQUÊNCIA DIDÁTICA BASEADA NO MÉTODO RECEPCIONAL}

O Método Recepcional, trabalho das autoras Maria da Glória Bordini e Vera Teixeira Aguiar (1993), representa uma inovação no ensino de literatura, uma vez que traz para o foco da questão a posição do leitor (no caso, o estudante) frente ao texto lido. A partir desse método de ensino, priorizam-se as opiniões e as impressões do leitor no ato da leitura para, a partir disso, realizarem-se o diálogo e o debate com o professor. Tal debate é dividido em cinco passos que devem ser seguidos sem ultrapassar ou deletar nenhum deles, pois eles funcionam como uma ponte que liga um ao outro.

Ademais, este método consiste em analisar o fenômeno literário a partir da visão do leitor, promovendo, portanto, uma atitude participativa do aluno com os inúmeros textos literários.

A seguir, é proposto um exemplo de como trabalhar o poema "Quebranto" na biblioteca com os alunos, do escritor, dramaturgo e poeta contemporâneo brasileiro, Luiz Silva, mais conhecido pelo pseudônimo Cuti, tendo em vista que será mostrado a estes de forma integral $e$ objetivando o entendimento real do texto literário.

- Determinação do horizonte de expectativas: primordialmente, antes de apresentar o poema aos leitores, é necessário que o mediador aborde brevemente assuntos sobre as particularidades de um poema e, sobretudo, acerca da Literatura AfroBrasileira, bem como suas características e sua importância como patrimônio histórico e artístico. Depois, pode-se falar de forma sucinta sobre o poeta no intuito de que os alunos possam ter uma noção de como seus valores éticos e culturais são incorporados em suas obras.

- Atendimento do horizonte de expectativas: no momento da leitura, o professor pode imprimir o poema e o distribuir aos leitores para realizarem uma leitura individual. Após esse primeiro momento, é necessário que o professor leia o poema em voz alta para a turma, respeitando suas pausas e suas entonações na voz, a fim de dar maior credibilidade ao gênero e provocar nos discentes situações de proximidade com o texto. Por fim, pode haver um debate sobre o que foi lido, abrindo espaço para os alunos refletirem e opinarem sobre como o eu lírico apresenta a figura do negro no texto.

- Ruptura do horizonte de expectativas: conforme dito anteriormente, o poema aborda conteúdos relacionados à discriminação, racismo e tantos outros, como ruptura desse horizonte, o professor pode apresentar aos alunos um vídeo da música "A Carne", de Elza Soares lançada pela primeira vez no ano de 2002, que trata sobre a figura do negro. Ademais, mais especificamente, o professor pode trabalhar com a estrofe abaixo, objetivando a participação de todos com reflexões, posicionamentos críticos, interpretação individual e coletiva.

$$
\begin{array}{r}
\text { “A carne mais barata do } \\
\text { mercado } \\
\text { É a carne negra } \\
\text { Que vai de graça pro presídio } \\
\text { E para debaixo do plástico } \\
\text { E vai de graça pro sub-emprego } \\
\text { E pros hospitais psiquiátricos.” }
\end{array}
$$

- Questionamento do horizonte de expectativas: a partir das respostas e dos resultados adquiridos das reflexões na etapa anterior, o docente pode solicitar que os alunos 
anotem a relação existente entre a música e o poema, além de solicitar que escrevam sobre suas experiências em cada leitura realizada. Após finalizarem as anotações, os alunos podem ler uns para os outros, no intuito de fazer com que percebam os diversos entendimentos que um texto possibilita.

- Ampliação do horizonte de expectativas: como forma de ampliar o horizonte de expectativas dos alunos, o docente pode, juntamente com a ajuda do professor de Sociologia da escola, desenvolver uma espécie de "café com Sociologia" na biblioteca escolar para debaterem sobre assuntos sociais que foram mostrados tanto no poema quanto na música, como o racismo, por exemplo. Os professores devem abrir espaço para que os discentes se sintam confortáveis em falar sobre esse assunto, deixando-os livres para refletirem sobre o processo histórico desumano pelo qual os negros tiveram que enfrentar e que, infelizmente, até hoje enfrentam.

\section{CONCLUSÃO}

Em linhas gerais, percebe-se que a leitura de obras literárias pode acontecer nas aulas de Literatura e de forma bastante proveitosa, desde que sejam adotadas metodologias que coloquem o aluno no centro do processo de aprendizagem. Assim, o modelo de sequência mostrada surge como uma metodologia que prioriza questões essenciais no que se refere à leitura, como a leitura integral de textos, entrosamento positivo entre os alunos, participação coletiva e tantos outros.

Neste trabalho, enfatizou-se a necessidade de ler obras literárias de modo integral, desconsiderando assim, leituras fragmentadas, textos como pretextos e leituras fincadas no historicismo literário.

Diante disso, percebe-se que, quando se adotam metodologias e abordagens eficientes (como a sequência didática, por exemplo), os alunos podem demonstrar um maior interesse pela leitura e uma maior participação nas etapas do modelo apresentado. Metodologias como as que foram apresentadas, portanto, contribuem no processo de construção do leitor, visando sua autonomia perante o mundo.

Debateu-se, também, sobre o processo da mediação de leitura como um ponto importante que deve possuir destaque não só nas práticas, mas também nos serviços realizados nas bibliotecas. Além disso, relacionou-se mediação de leitura com o espaço da biblioteca, tendo em vista que foram apontados como os pontos principais e mais presentes na elaboração de projetos e ações que objetivam o fomento à leitura.

Por fim, o artigo se mostra de grande destaque para o meio acadêmico por exemplificar como a biblioteca pode ser um espaço de reconstrução de conhecimento e, sobretudo, como um espaço estimulador de leitura, uma vez que é neste espaço que os alunos podem ter o primeiro contato com o universo literário.

A biblioteca, surge, portanto, como um meio no qual podem ser inseridas metodologias como o da sequência didática abordada neste trabalho, posto que se trata apenas de uma proposta que pode servir como um exemplo de abordagem literária em os agentes podem adotar na biblioteca escolar, a fim de que os leitores se aproximem das obras literárias por simplesmente gostar, pela fruição, e não mais como antigamente era proposto, isto é, como uma obrigação. Por fim, vale ressaltar que o modelo de sequência didática baseada no método recepcional apresentado pode ser mudado e reformulado, sendo possível estabelecer uma sequência com qualquer outro tipo de texto ou obra. 


\section{REFERÊNCIAS}

FECOMERCIO-RJ - 70\% dos brasileiros não leram em 2014, diz pesquisa da. Jornal da Globo, 2015. Disponível em: <http://g1. globo.com/jornal-da-globo/noticia/ 2015/04/70-dos-brasileiros-nao-leram-em2014-diz-pesquisa-da-fecomercio-rj.html>. Acesso em: 14 de out. de 2019.

BAJOUR, Cecília. Ouvir nas entrelinhas: o valor da escuta nas práticas de leitura. São Paulo: Editora Pulo do Gato, 2012.

BORDINI, Maria da Glória; AGUIAR, Vera T. de. Literatura a formação do leitor: alternativas metodológicas. 2. ed. Porto Alegre: Mercado Aberto, 1993.

CAGLIARI, Luiz Carlos. Alfabetização \& Linguística. 8 ed. São Paulo, SP: Scipione. 1995.

CANDIDO, Antonio. O direito à literatura. In: Vários escritos. 3. ed. São Paulo: Duas Cidades, 1995, p. 169-191.COSSON, Rildo. Letramento literário: teoria e prática. São Paulo: Editora Contexto, 2007.

COSSON, Rildo. Letramento literário: teoria e prática. São Paulo: Contexto, 2007.

FREIRE, P. Pedagogia do oprimido. 49. ed. Rio de Janeiro: Paz e Terra, 2010.
INDURSKY, Freda; ZINN, Maria Alice Kaner. Leitura Como Suporte Para a Produção Textual. Revistas Leitura Teoria e Prática, No 5, 1985.

RANGEL, Jurema Nogueira Mendes. Leitura na escola: espaço para gostar de ler. Porto Alegre: Mediação, 2009.

SILVA, Ezequiel Theodoro. Leitura na escola e na biblioteca. 3. ed. Campinas (SP): Papirus, 1991.

SILVA, Luiz. Quebranto. Disponível em: <https://www.lyrikline.org/pt/poemas/quebr anto-1311>. Acesso em: 02 de nov. de 2019.

SOARES, Elza. A carne. Disponível em: <https://youtu.be/yktrUMoc1Xw>. Acesso em: 03 de nov. de 2019. 